\title{
First Report of Agrobacterium rhizogenes-induced Hairy Root Formation in Selaginella bryopteris: Pteridophyte Recalcitrant to Genetic Transformation
}

Ravi Shankar Singh ${ }^{1^{\star}}$

https://orcid.org/0000-0002-1556-1340

\section{Vikash Kumar Jha ${ }^{1}$}

https://orcid.org/0000-0003-1944-7374

Tirthartha Chattopadhyay ${ }^{1}$

https://orcid.org/0000-0001-5654-0303

\author{
Ujjwal Kumar ${ }^{1}$ \\ https://orcid.org/0000-0002-6724-4056 \\ Devanand Pralhad Fulzele ${ }^{2}$ \\ https://orcid.org/0000-0002-6714-3589 \\ Prabhash Kumar Singh ${ }^{1}$ \\ https://orcid.org/0000-0002-8112-7948
}

${ }^{1}$ Bihar Agricultural University, Department of Plant Breeding and Genetics, Sabour, Bhagalpur, Bihar, India. ${ }^{2 B h a b h a}$ Atomic Research Centre, Nuclear Agriculture and Biotechnology Division, Plant Biotechnology and Secondary Metabolites Section, Mumbai, India

Received: 2018.12.01; Accepted: 2020.02.13.

*Correspondence: ravi.molbio@gmail.com; Tel: +91-77-81896931

\section{HIGHLIGHTS}

- A. rhizogenes (strain LBA1334) co-cultivation with explants (root, rhizophore, stem portion near the root, and stem with intact fronds) of S. bryopteris led to induction of hairy roots after 6 days of infection in case of $48 \mathrm{~h}$ co-cultivation only.

- Out of different media like MS, SHFR (Stage Hog Fern Root) and KNOP's, SHFR showed good response in transformation as well as propagation.

- PCR with rol $\mathrm{A}$ and vir $\mathrm{C}$ gene specific primers confirmed the Ri T-DNA integration in induced hairy roots.

- Addition of TDZ (2 mg/L) and Bevistin (0.1\%) in SHFR media enhanced the transformation efficiency.

Abstract: we report $A$. rhizogenes-induced hairy root formation in $S$. bryopteris, a medicinally and commercially important plant. A. rhizogenes strain LBA1334 co-cultivated with explants (root, rhizophore, stem portion near the root, and stem with intact fronds) for 24 and $48 \mathrm{~h}$ after transformation for induction of hairy roots. The induction of hairy root was observed after 6 days of infection in case of $48 \mathrm{~h}$ co-cultivation only. PCR with rol A and vir $\mathrm{C}$ gene specific primers confirmed the induced hairy roots were due to Ri T-DNA integration and not due to contaminating $A$. rhizogenes. The root network as explants showed the maximum transformation efficiency. We tested different media like MS, SHFR (Stage Hog Fern Root) and KNOP's during transformation for hairy root induction. The SHFR based media showed good response in transformation as well as propagation. Further, transformation efficiency was enhanced by addition of TDZ $(2 \mathrm{mg} / \mathrm{L})$ and Bevistin $(0.1 \%)$ in SHFR media. The present work would be helpful in hairy roots-based in vitro production of secondary metabolites and on aspect of functional genomics of $S$. bryopteris. 
Keywords: Selaginella bryopteris; hairy roots; Agrobacterium rhizogenes.

\section{INTRODUCTION}

The hairy roots of different plants are being harnessed for the in vitro production of valuable phytochemicals of medicinal and commercial importance and for wide range of uses such as pharmaceuticals, pesticides, cosmetics, food additives etc. The hairy root culture (HRC)-based in vitro productions were reported for bioactive molecules such as shikonins, azadirachtin, camptothecins, harpagide, ginsenosides, paclitaxel, hyoscyamine and scopolamine [1-5]. Hairy root formation is induced by Agrobacterium rhizogenes and it often grows comparatively as fast as or faster than plant cell cultures [6,7]. Many valuable secondary metabolites are synthesized in roots in vivo, and often synthesis is linked to root differentiation [7]. HRCs have been successfully employed also in cases where secondary metabolites accumulate only in the aerial part of an intact plant. HRC is promising for in vitro production of metabolites; it could be more biosynthetically efficient as compared to their mother plants [8]. Several metabolites irrespective of their origin or site of production, such as lawsone and artemisinin generally accumulates in the aerial part of the plant, but these are also produced in hairy roots $[9,10]$. It is reported that the plants producing high levels of secondary metabolites usually generate high-producing cell lines [11]. The preference for hairy roots is due to their genetic stability and faster growth rate, ability to produce secondary metabolites over successive generations without losing genetic or biosynthetic stability [12]. High branching and high growth rate of these roots suits for commercial up-scaling even in bioreactors [13].

Selaginella species are enriched with bioactive molecules such as flavonoids, biflavonoids, lignans, selaginellins, alkaloids, terpenoids and other phenolics [14,15]. Selaginella bryopteris (L.) Baker (family, Selaginellaceae) is one of the Selaginella species widely distributed in India and being used as folklore medicine since time immemorial [16-18]. To date no effort has been made for optimization of genetic transformation for hairy root induction in S. bryopteris. As the Agrobacterium-mediated transformation methods are not very successful in pteridophytes, deciphering functionality of genes required heterologous system such as Arabidopsis thaliana, Escherichia coli and Saccharomyces cerevisiae. Previously, A. tumefaciens-mediated stable transformation of two ferns (pteridophytes), Pteris vittata and Ceratopteris thalictroides were reported [19], with constructs containing the P. vittata actin promoter driving a GUS Plus reporter gene that led to recovery of transgenic sporophytes.

Earlier we initiated molecular works on $S$. bryopteris and reported RNA-Seq based transcriptome analysis and cloning and characterization of MYB transcription factors genes [20,21], and also evaluated anti-microbial properties of this important medicinal plant [22]. To the best of our knowledge, this is the first report on A. rhizogenes-mediated genetic transformation for induction of hairy roots in S. bryopteris or any other pteridophyte. In view of medicinal and commercial importance of S. bryopteris, the efficient and stable in vitro production method is highly desired. Therefore, there is good prospect of HRC for in vitro production of flavonoids/biflavonoids in S. bryopteris and for use in functional genomics.

\section{MATERIALS AND METHODS}

\section{Plant material and culture}

S. bryopteris plants were collected from Hills near Sheikhpura town, Bihar, India and maintained in pot containing soil, sand, compost (1:1:1) ratio in the garden of Bihar Agricultural University, Sabour, Bhagalpur, Bihar (India). Explants such as rhizophore, stem and fronds of S. bryopteris were cut properly and washed with tap water till no soil or dusts are visible. Further, explants were treated with Bevistin $(0.5 \%)$ and kept on incubator shaker for $2 \mathrm{~h}$, then washed with Tween-20 (0.2\%) for $20 \mathrm{~m}$. and with RinAlla ${ }^{8}(5 \%$ bleach/sodium hypochloride) for a short while. After these steps, it was washed with sterile distilled water for several times under laminar Air-flow chamber. Finally, it was treated with $0.1 \% \mathrm{HgCl} 2$ (Hi-Media, India) for $1 \mathrm{~m}$. and washed with sterile water thoroughly and dried on filter paper. These dried explants were cultured on MS basal media [23].

\section{Preparation of different media}

Different media with varying compositions were tested during transformation with explants. These media were primarily MS based [23] and Stage Hog Fern Root medium (SHFR, Hi-Media, India), modified as per need with plant growth regulators (PGRs), for propagation and transformation experiments. The composition of media were as follows: (1) MS resuspension media [transformation media; in $100 \mathrm{~mL}$ it contained MS-Salt 
$=0.220 \mathrm{~g}$, Glucose $=0.8 \mathrm{~g}$, Sucrose $=1.5 \mathrm{~g}, \mathrm{KCl}=0.04 \mathrm{~g}, \mathrm{MgCl} 2=0.6 \mathrm{~g} ; \mathrm{pH}$ maintained at $5.2,50 \mu \mathrm{L}$ acetosyringone $(50 \mathrm{mg} / \mathrm{ml})$ after autoclaving]; (2) MS co-cultivation media [in $100 \mathrm{~mL}$ it contained MS-salt $=0.442 \mathrm{~g}$, Sucrose $=3 \mathrm{~g}$, Kinetine $=200 \mu \mathrm{l}(1 \mathrm{mg} / \mathrm{mL})$, Thidiazuron $(T D Z)=100 \mu \mathrm{L}(2 \mathrm{mg} / \mathrm{mL})$, Agar $=0.8 \mathrm{~g}$, $\mathrm{pH}$ maintained at 5.8, $200 \mu \mathrm{L}$ cefotaxime $(250 \mathrm{mg} / \mathrm{mL})$ after autoclaving]; (3) modified Stag Horn Cocultivation media [SHFR; in $100 \mathrm{~mL}$ it contained SHFR Media $=4.2 \mathrm{~g}$ (Hi-Media, India), TDZ ${ }^{*}=100 \mu \mathrm{L}(2$ $\mathrm{mg} / \mathrm{mL}$; * variable quantity of hormone was used), Bevistin $=0.2 \mathrm{~g}$, Agar $=0.4 \mathrm{~g}, 200 \mu \mathrm{L}$ cefotaxime $(250$ $\mathrm{mg} / \mathrm{mL}$ ) after autoclaving]; and (4) Root propagation media [MS-based: MS-salt $=0.442 \mathrm{~g}$, Agar $=0.8 \mathrm{~g}$, Bevistin $=0.2 \mathrm{~g}$, TDZ $^{*}=50 \mu \mathrm{L}(2 \mathrm{mg} / \mathrm{mL}$; * variable quantity used $)$; and SHFR media based: SHFR $=4.4 \mathrm{~g}$, Agar $=0.4 \mathrm{~g}, \mathrm{TDZ}^{*}=50 \mu \mathrm{L}\left(2 \mathrm{mg} / \mathrm{mL} ;{ }^{*}\right.$ variable quantity used $\left.)\right]$.

\section{Protocol for co-cultivation and induction of hairy roots}

Different A. rhizogenes strains, like MTCC 532 and MTCC 2364 (procured from CSIR- Institute of Microbial Technology, Chandigarh, India, and LBA1334 [24]; procured from procured from Indian Institute of Technology, Kharagpur, India) were used in the present study. At first two strains MTCC 532 and MTCC 2364 were used for the transformation of $S$. bryopteris in the presence of acetosyrigone for the induction of hairy roots. Later, strain LBA1334 was used for the same. In brief, the protocol was as follows, for cocultivation, the strains were grown at $28^{\circ} \mathrm{C}$ in an incubator shaker with shaking (150 rpm) for $48 \mathrm{~h}$ in LB media $(\mathrm{OD} 600=1.0)$ and harvested by centrifugation at $6000 \mathrm{rpm}$. The pellet was resuspended with MSresuspension media. The explants were pierced with sterile needle and immersed in the bacterial broth culture and incubated on incubator shaker at $100 \mathrm{rpm}$ for $30 \mathrm{~m}$. The explants were blot dried to remove excess of bacterial inoculums. All the explants were co-cultivated on MS-transformation media with acetosyrigone (Table 1) at $25^{\circ} \mathrm{C}$ in dark on incubator shaker for $24 \mathrm{~h}$, and $48 \mathrm{~h}$ in two separate flasks. Then these explants were transferred on MS medium devoid of growth regulators and supplemented with $3 \%$ sucrose, cefotaxime (200 mg/L) and solidified with $0.8 \%$ agar (w/v). Hairy roots at the end of 15 days excised individually from the infected site were and transferred to MS medium containing $200 \mathrm{mg} / \mathrm{L}$ of cefotaxime.

\section{Confirmation of transformation and isolation of genomic DNA}

Genomic DNA was isolated from hairy roots of $S$. bryopteris using CTAB method [25]. Plasmid from $A$. rhizogenes was isolated according to the alkaline lysis plasmid isolation protocol [26]. The Polymerase Chain Reaction (PCR) was used to detect the Ri T-DNA integration in hairy roots. PCR was performed to detect the rol A gene using rol A gene specific primers, Forward: 5'-AGA ATG GAA TTA GCC GGA CTA-3' and Reverse: 5'-GTA TTA ATC CCG TAG GTT TGT TT-3' (Xcelris Genomics, India). The PCR mixture $(25 \mu \mathrm{L})$ contained $50 \mathrm{ng}$ of DNA prepared from normal and hairy roots respectively as the template, PCR was carried out on a thermal cycler (Veriti®\#9902, ABI, Singapore) as follows:, 10X PCR Buffer $2.5 \mu \mathrm{L}$, dNTPs (10 mM) $0.5 \mu \mathrm{L}$, Forward Primer $(10.0 \mu \mathrm{M}) 0.5 \mu \mathrm{L}$, Reverse Primer $(10.0 \mu \mathrm{M}) 0.5 \mu \mathrm{L}$, Taq DNA Polymerase $(5.0 \mathrm{U} / \mu \mathrm{L}$; Xcelris Genomics, India) $0.25 \mu \mathrm{L}$ and autoclaved distilled water $19.75 \mu \mathrm{L}$ to make total reaction volume 25 $\mu \mathrm{L}$. PCR for rol A was carried out by amplifying with initial denaturation at $94{ }^{\circ} \mathrm{C}$ for $5 \mathrm{~m}$, followed by 35 cycles of $1 \mathrm{~m}$ denaturation at $94^{\circ} \mathrm{C}, 30 \mathrm{~s}$ annealing at $55^{\circ} \mathrm{C}$ and $1 \mathrm{~m}$ extension at $72{ }^{\circ} \mathrm{C}$ with a final extension of 72 ${ }^{\circ} \mathrm{C}$ for $10 \mathrm{~m}$. In control, the amplification of vir $\mathrm{C}$ gene (Forward: 5'-ATC ATT TGT AGC GAC T-3' and Reverse: 5'-AGC TCA AAC CTG CTT C-3'). The PCR conditions were same as those used for amplifying the rol A gene.

\section{RESULTS AND DISCUSSION}

HRC has become one of the methods of choice recently for the production of secondary metabolites in different uncultivated or endangered medicinal plants. These roots show genetic stability and can be indefinitely propagated on a synthetic medium without the use of plant growth regulators [11,27]. Further, hairy root also yields high levels of secondary metabolites in contrast to cell culture, an advantage it has due to differentiation of tissue. The hairy roots could also serve the purpose in functional genomics. Hairy rootbased transformation system for functional characterization of genes/enzymes of Selaginella is not available. Therefore, the model plants, Arabidopsis and rice were being employed up till now for functional study of Selaginella genes/enzymes [14].

A. rhizogenes-mediated genetically transformed HRCs are more biosynthetically efficient and genetically stable for secondary metabolite production [28-30]. These hairy roots offer unique advantages in their genetic and biosynthetic stability [31]. Hairy roots are considered a very good system for continuous synthesis of valuable metabolic compounds in an aseptic condition in the absence of expensive growth regulators in the culture medium [12,13]. HRCs of Brassica juncea and Chenopodium amaranticolor were reported to be developed by genetic transformation using $A$. rhizogenes for removal of uranium from the solution of 
concentration up to 5,000 $\mu \mathrm{M}$ [32]. HRCs of Cichorium intybus and $B$. juncea were used for their ability to uptake and degrade DDT (1,1,1-trichloro-2,2-bis-(4'-chlorophenyl)ethane) suggest the potential applicability and advantage of using these plant species for phytoremediation of persistent xenobiotics such as DDT in an eco-friendly and efficient manner for environmental cleanup [33].

\section{Confirmation of Hairy root resulting from Ri T-DNA integration}

A. rhizogenes induced hairy roots formation was achieved in S. bryopteris (Figure 1, panel a). PCR with rol A gene specific primer yielded a $308 \mathrm{bp}$ size fragment thereby showing the Ri T-DNA integration in hairy roots (Figure 1, panel b). Further, vir $\mathrm{C}$ genes specific primers used to detect the presence of contaminating $A$. rhizogenes in the hairy roots yielded $780 \mathrm{bp}$ amplicon in positive control 1 but no amplification was detected in hairy root line (Figure 1, panel b). Thus, these results confirmed that these developed hairy root lines resulted from Ri T-DNA integration and not due to contaminating $A$. rhizogenes. These hairy roots were sub-cultured on MS medium without PGR (i-iv) at day 0, 5, 10, 15, respectively (Figure 1 panel c).

a.
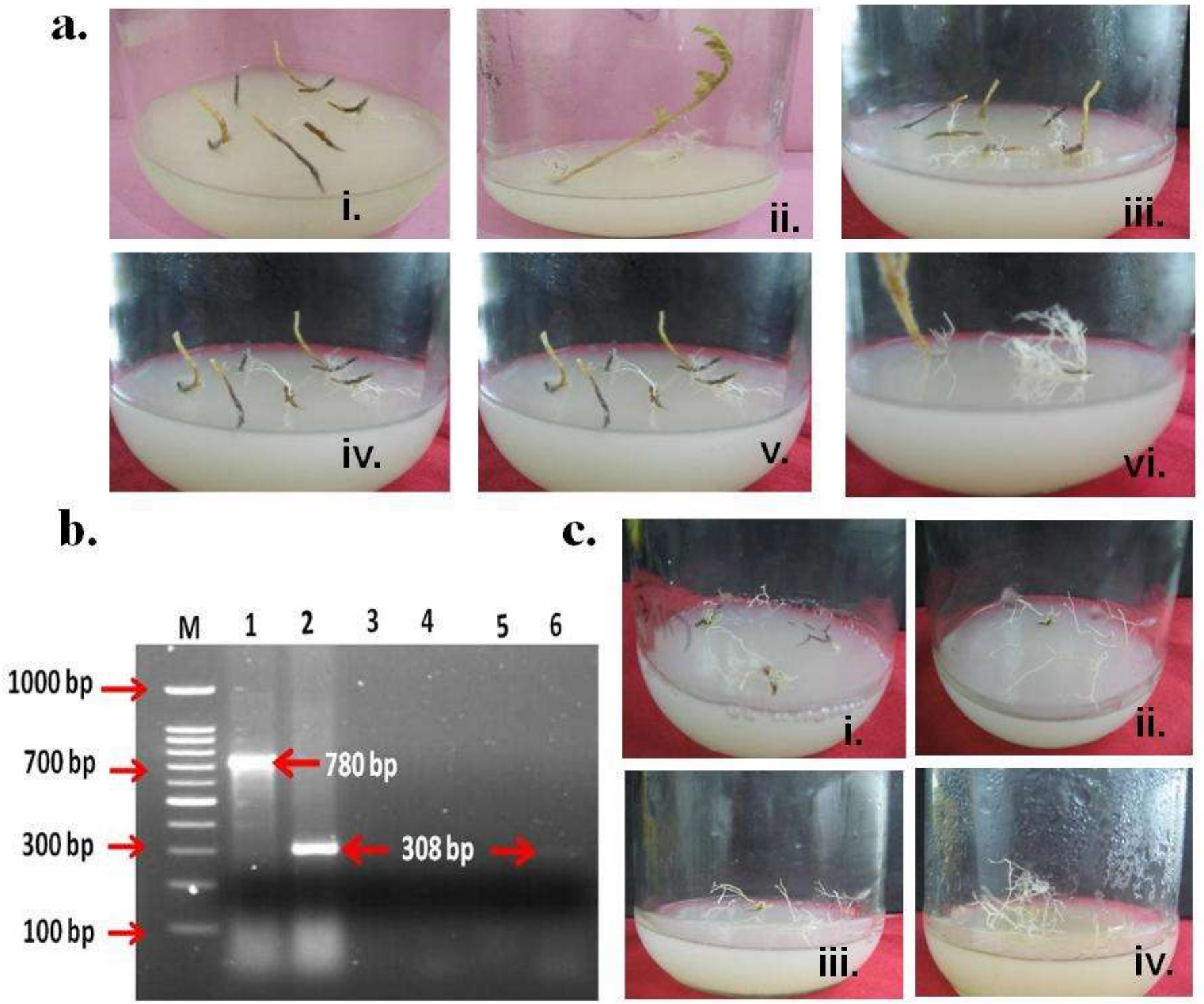

Figure 1. Hairy root induction by $A$. rhizogenes in $S$. bryopteris using root, rhizophore, stem portion near the root, and stem with intact fronds (i-vi) at day $7^{\text {th }}, 15^{\text {th }}$ and $20^{\text {th }}$, respectively on MS medium with cefotaxime $(200 \mu \mathrm{g} / \mathrm{ml})[\mathrm{Panel}$ a]. PCR confirmations of hairy roots using rol A gene specific primers; M. 100 bp DNA marker, 1. vir $\mathrm{C}$ gene amplification with $A$. rhizogenes (positive control 1), 2. rol A gene amplification with $A$. rhizogenes (positive control 2),3. vir $\mathrm{C}$ gene amplification without any template (negative control 1), 4. rol A gene amplification without any template (negative control 2), 5. vir $\mathrm{C}$ gene amplification in hairy root line, and 6. rol A gene amplification in hairy root line [Panel b]. Subculture of hairy roots on MS medium without PGR (i-iv) at day $0,5,10,15$, respectively [Panel $\mathrm{c}]$. 
Effects of A. rhizogenes strains, co-cultivation period, types of explants, media, and PGRs on hairy root induction

\section{A. rhizogenes strains}

Variations in virulence of bacteria, genotype of plant and type of explants play an important role in determining the frequency of hairy root induction. The virulence of the $A$. rhizogenes strains varies according to the strain and affects the frequency of the hairy root production [34]. In our experiment, two MTCC series strains (MTCC 532 and 2364) were used in the beginning but it failed to induce hairy root formation in $S$. bryopteris. Earlier in Withania somnifera transformation with these strains of A. rhizogenes (MTCC 2364, MTCC 532 including R1000), showed that strain R1000 as more effective for inducing hairy roots (50.6\%), while MTCC $2364(29.3 \%)$ and MTCC 532 (18.6\%) were less efficient [34]. Realizing the virulence and recalcitrance in pteridophytic plant like S. bryopteris to transformation, another strain of $A$. rhizogenes, LBA 1334 was used. This strain was found to be effective and the present study of standardization of protocol is based on this strain only.

\section{Co-cultivation period}

To see the effect of co-cultivation period the strain LBA1334 was grown along with explants for 24 and $48 \mathrm{~h}$. The induction of hairy root after 6 days of infection was observed in case of $48 \mathrm{~h}$ co-cultivation only. The infection period along with co-cultivation period affected the hairy root induction $[35,36]$.

\section{Type of explants}

Keeping in view the recalcitrant nature of $S$. bryopteris, different parts of plant, root, rhizophore, stem portion near the root, and stem with intact fronds were used as explants in transformation for hairy root induction (Figure 1, panel a; Table 1). The root network as explants showed the maximum transformation efficiency $(70 \%)$.It was reported that the types of explants due to its meristematic activity influence the hairy roots production [37]. In Berberis aristata, callus was reported to be better explants in comparison to nodal segment and leaf [36].

\section{Media}

We tested different media like MS-based, SHFR and KNOP's media during transformation for hairy root induction (Table 1). The SHFR based media observed good response in transformation $(80 \%)$ as well as propagation and induction time was 6 days. Liquid media of all combination have not observed good response. MS-based media did not show any response for propagation of hairy root of S. bryopteris, while KNOP showed $10 \%$ response. Different ionic strength media affects the hairy roots cultures in terms of biomass and metabolite production. In hairy root culture of $A$. indica, media varying in ionic strength such as $\mathrm{ON}, \mathrm{MS}$ and B5 used yielded maximum amounts of biomass and azadirachtin in correlation with their ionic strength [1]. ON medium that contained higher ionic concentrations of inorganic salts compared to MS and B5, was found to favour the growth and azadirachtin production.

\section{PGRs}

The ability of hairy roots to grow rapidly in the absence of exogenous plant growth regulators (PGRs) and produce the same compounds found in the parental plants, makes it suitable tool for production of secondary metabolites and recombinant proteins [11]. In the present study, SHFR media was modified with plant growth regulators (PGRs), Kinetin and TDZ with or without addition of Bevistin (Table 1). SHFR media along with TDZ $(2 \mathrm{mg} / \mathrm{L})$ and Bevistin $(0.1 \%)$ enhanced the transformation efficiency and propagation of hairy roots. While Kinetin (2 mg/L) and TDZ alone response was $40 \%$ and $65 \%$, respectively. 
Table1. Effect of type of explants, different media composition, and different PGRs on hairy root induction efficiency a.Type of explants

Type of explants Total number No. of hairy root Time taken for induction of hairy root of explants forming explants

\begin{tabular}{llll}
\hline Root & 10 & $7(70 \%)$ & Early \\
Rhizophore & 10 & $5(50 \%)$ & Normal \\
Stem near root & 10 & $5(50 \%)$ & Normal \\
Stem with frond & 10 & $3(30 \%)$ & Late \\
\hline
\end{tabular}

\begin{tabular}{|c|c|c|c|}
\hline \multicolumn{4}{|c|}{ b. Different media composition } \\
\hline Co-cultivation media & $\begin{array}{l}\text { Frequency of } \\
\text { hairy root } \\
\text { formation }\end{array}$ & $\begin{array}{l}\text { Time taken in } \\
\text { response (days) }\end{array}$ & $\begin{array}{l}\text { Growth pattern of hairy root } \\
\text { (propagation) }\end{array}$ \\
\hline MS-based & $\begin{array}{l}\text { No Root } \\
\text { Formation } \\
\text { (0 in 10) }\end{array}$ & - & - \\
\hline Stag Hog based & $\begin{array}{l}8 \text { in } 10(80 \%) \text { all } \\
\text { type }\end{array}$ & 6 & Efficient \\
\hline KNOP (liquid) & $\begin{array}{l}1 \text { in } 10(10 \%) \text { in } \\
\text { root network } \\
\text { only }\end{array}$ & 20 & Slow \\
\hline $\begin{array}{l}\text { c. Different PGRs } \\
\text { Combination of PGRs }\end{array}$ & $\begin{array}{l}\text { Regeneration } \\
\text { frequency of } \\
\text { explants (\%) }\end{array}$ & $\begin{array}{l}\text { Regeneration } \\
\text { response (in day) }\end{array}$ & $\begin{array}{l}\text { Rate of growth } \\
\text { (comparative)/ Visual observation } \\
\text { (star) }\end{array}$ \\
\hline SHFR + TDZ & 65 & 6 & Good/4 \\
\hline SHFR + KINETIN & 40 & 10 & Slow/2 \\
\hline SHFR+TDZ+ KINETIN & 60 & 6 & Good/3 \\
\hline $\begin{array}{l}\text { SHFR+TDZ+ KINETIN } \\
+ \text { Bevistin }\end{array}$ & 70 & 6 & Good/3 \\
\hline SHFR+TDZ+ Bevistin & 75 & 6 & Better in all/5 (best) \\
\hline $\begin{array}{l}\text { SHFR+KINETIN+ } \\
\text { Bevistin }\end{array}$ & 50 & 10 & Slow/3 \\
\hline
\end{tabular}

\section{CONCLUSION}

In S. bryopteris an efficient, stable and viable alternative in vitro method is desired for the production of bioactive molecules and HRC-based system is most suited for this. The present work would be helpful in $\mathrm{HRC}$-based in vitro production of bioactive molecules and on aspect of functional genomics of $S$. bryopteris.

Author contributions: Conceived the idea and designed the experiment: RSS; performed the experiments: RSS, VKJ, UK; result/data interpretation: RSS, TC and VKJ; valuable suggestions and overall guidance during the experimentation: DPF and PKS; prepared and edited the manuscript: RSS and TC.

Acknowledgement: Authors thanks the Board of Research in Nuclear Sciences (BRNS), Department of Atomic Energy (DAE), India for funding the project entitled "Bioprospecting and characterizing bioactive molecules from Arnebia euchroma and Selaginella bryopteris, and enhancing their in vitro production using gamma irradiation" (2013/35/39/BRNS/1362). The authors also thank Professor Adinpunya Mitra and Professor Mrinal K. Maiti for providing the A. rhizogenes strain LBA1334 and CSIR-Institute of Microbial Technology, Chandigarh, India for providing the strains MTCC 532 and MTCC 2364. All the supports and facilities provided by Bihar Agricultural University, Sabour is duly acknowledged. This manuscript bears Bihar Agricultural University communication No. 435/2018.

Conflict of interest: Authors declare that there are no conflicts of interest.

\section{REFERENCES}

1. Satdive RK, Fulzele DP, Eapen S. Enhanced production of azadirachtin by hairy root cultures of Azadirachta indica A. Juss by elicitation and media optimization. J Biotechnol. 2007; 128: 281-9.

2. Sirikantaramas S, Sudo H, Asano T, Yamazaki M, et al. Transport of camptothecin in hairy roots of Ophiorrhiza pumila. Phytochem. 2007; 68: 2881-6. 
3. Syklowska-Baranek K, Pietrosiuk A, Kokoszka A, Furmanowa, M. Enhancement of taxane production in hairy root culture of Taxus x media var. Hicksii. J Plant Physiol. 2009; 166:1950-4.

4. Chaudhury A, Pal M. Induction of shikonin production in hairy root cultures of Arnebia hispididdima via Agrobacterium rhizogenes-mediated genetic transformation. J Crop Sci Biotech. 2010; 13: 99-106.

5. Moharrami F, Hosseini B, Sharafi A. Farjaminezhad M. Enhanced production of hyoscyamine and scopolamine from genetically transformed root culture of Hyoscyamus reticulatus $\mathrm{L}$. elicited by ironoxide nanoparticles. In Vitro Cell Dev Biol Plant. 2017; 53(2):104-11.

6. Charlwood BV, Charlwood, KA. Terpenoid production in plant cell culture. In: Ecological chemistry and biochemistry of plant terpenoids; Harborne, J. B., Tomas Barberan, F. A. Eds.; Oxford: Clarendon Press; 1991; p. 95-132.

7. Flores HE, Vivanco JM, Loyola-Vargas VM. Radicle biochemistry: the biology of root-specific metabolism. Trends Plant Sci. 1999; 4:220-6.

8. Kittipongpatana N, Hock RS, Porter JR. Production of solasodine by hairy root, callus, and cell suspension cultures of Solanum aviculare Forest. PCTOC. 1998; 52:133-43.

9. Bakkali AT, Jaziri M, Foriers A, Vander HY, Vanhaelen M. Home`s J. Lawsone accumulation in normal and transformed cultures of henna, Lawsonia inermis. PCTOC. 1997; 51:83-7.

10. Liu C, Wang YC, Zhao B, Guo C, Ouyang F, Ye HC, Li GF. Development of a nutrient mist bioreactor for growth of hairy roots. In Vitro Cell Develop Biol - Plant. 1997; 35:271-4.

11. Kim Y, Wyslouzil BE, Weathers PJ. Secondary metabolism of hairy root cultures in bioreactors. In Vitro Cell Develop Biol - Plant. 2002; 38: 1-10.

12. Giri A, Narasu ML. Transgenic hairy roots: recent trends and applications. Biotech Adv. 2000; 18(1):1-22.

13. Hu ZB, Du M. Hairy root and its application in plant genetic engineering. J Integr Plant Biol. 2006; 48:121-7.

14. Weng JK, Noel JP. Chemo-diversity in Selaginella: a reference system for parallel and convergent metabolic evolution in terrestrial plants. Front Plant Sci.2013; 4: 1-17.

15. Zou Z, Xu K, Xu P, Li X, Cheng F, Li J, Yu X, Cao D, Li D, Zeng W, Zhang G, Tan G. Seladoeflavones A-F, six novel flavonoids from Selaginella doederleinii. Fitoterapia. 2017; 116: 66-71.

16. Sah NK, Singh SNP, Sahdev S, Banerji S, Jha V, Khan Z, Hasnain SE. Indian herb "Sanjeevani"(Selaginella bryopteris ) can promote growth and protect against heat shock and apoptotic activities of ultraviolet and oxidative stress. J Biosci. 2005; 30: 499-505.

17. Sah P. Does the magical Himalayan herb "Sanjeevani Booti" really exist in Nature? J American Sci. 2008; 4: 65-7.

18. Kumar A. Effect of elicitors on expression of MYB transcription factor genes in Selaginella bryopteris (L.) Baker. M.Sc. Thesis (2017), Bihar Agricultural University, Sabour, Bhagalpur, India. http://krishikosh.egranth.ac.in/handle/1/5810026093.

19. Muthukumar B, Joyce BL, Elless MP, Stewart Jr CN. Stable Transformation of Ferns Using Spores as Targets: Pteris vittata and Ceratopteris thalictroides. Plant Physiol. 2013; 163: 648-58.

20. Singh RS, Kesari R, Kumar U, Jha VK, Kumar A, Kumar T, Pal AK, Singh PK. Candidate genes of flavonoid biosynthesis in Selaginella bryopteris identified by RNA-Seq. FunctIntegrGenom.2018; 1-13.

21. Kumar A, Singh, RS, Kumar U, Rekha K, Thakur D, Pal AK, Singh PK. Expression of MYB Transcription Factor Genes in Response to Methyl Jasmonate, Salicylic Acid and Sodium Nitropruside in Selaginella bryopteris (L.) Baker. Intern J Agri Environ Biotech.2018; 11(2): 243-51.

22. Singh, RS; Thakur, D; Jha, VK; Kumar, U, Pal, AK; Singh, PK; Fulzele, D.P. Antibacterial activity of Selaginella bryopteris fronds extract on bacteria isolated from Mastititic milk. Int J Curr Microbial App sci. 2018; 7: 4711-15.

23. Murashige T, Skoog F. A revised medium for rapid growth and bioassays with tobacco tissue cultures. Physiol Plant. 1962;15:473-97.

24. Hooykaasv PJJ, Klapwijk PM, Nuti MP, Schilperoort RA, Rorsch A. Transfer of the Agrobacterium tumefaciens Ti plasmid to avirulent agrobacteria and to rhizobium ex planta. J Gen microbial. 1977; 98: 477-84.

25. Doyle JJ, Doyle JL. Isolation of plant DNA from fresh tissue. Focus. 1990; 12: 13-5.

26. Sambrook J, Fritrsch EF, Maniatis T. Molecular cloning: a laboratory manual, Cold Spring Laboratory Press, Cold Spring, Harbor, N.Y., 1989.

27. Eapen S, Mitra R. Plant hairy root cultures: prospects and limitations. Proceed Natl Acad Sci India. 2001; B67 (3 and 4):107-20.

28. AllanEJ, Eeswara JP, Jarvis AP, Mordue AJ, Morgan ED, Stuchbury T. Induction of hairy root cultures of Azadirachta indica A. Juss. and their production of azadirachtin and other important insect bioactive metabolites. Plant Cell Rep. 2002; 21: 374-9.

29. Srivastava S, Srivastava AK. Hairy root culture for mass-production of high-value secondary metabolites. Crit Rev Biotechnol. 2007; 27(1): 29-43.

30. Veena V, Taylor CG. Agrobacterium rhizogenes: recent developments and promising applications. In Vitro Cell Dev Biol Plant. 2007; 43: 383-403. 
31. Bapat VA, Ganapathi TR. Hairy roots -A novel source for plant products and improvement. Natl Acad Sci Lett. 2005; 28: 61-9.

32. Eapen S,Suseelan KN,Tivarekar S,Kotwal SA,Mitra R. Potential for rhizofiltration of uranium using hairy root cultures of Brassica juncea and Chenopodium amaranticolor. Environ Res.2003; 91(2):127-33.

33. Suresh B, Sherkhane PD,Kale S,Eapen S, Ravishankar GA. Uptake and degradation of DDT by hairy root cultures of Cichorium intybus and Brassica juncea. Chemosphere. 2005; 61(9):1288-92.

34. Chandrasekaran T, Soundar RC, Kandhan V, Abubakker A, Appakan S. Improved Agrobacterium rhizogenesmediated hairy root culture system of Withania somnifera (L.) Dunal using sonication and heat treatment. 3 Biotech. 2015; 5:949-56.

35. Giri A, Giri CC, Dhingra V, Narasu ML. Enhanced podophyllotoxin production from Agrobacterium rhizogenes transformed cultures of Podophyllum hexandrum.Nat Prod Lett.2001; 15: 229-35.

36. BrijwalL,Tamta S. Agrobacterium rhizogenes mediated hairy root induction in endangered Berberis aristata DC. Springer plus. 2015 Aug; 4: 443.

37. Bulgakov VP, Aminin DL, Shkryl YN, Gorpenchenko TY, Veremeichik GN, Dmitrenok PS, Zhuravlev YN. Suppression of reactive oxygen species and enhanced stress tolerance in Rubica cordifolia cells expressing thero/Concogene. Mol Plant Microbe Interact. 2008; 21: 1561-70.

(C) 2020 by the authors. Submitted for possible open access publication under the terms and conditions of the Creative Commons Attribution (CC BY NC) license (https://creativecommons.org/licenses/by-nc/4.0/). 